\title{
Usefulness of Various Peripheral Blood Leukocyte Count ratios in Malaria Evaluation
}

\author{
Akshay Louis Dias ${ }^{1}$ \& Sumanth $D^{2}{ }^{2}$ \\ ${ }^{1}$ UG Scholar, Department of Pathology, Fr Muller Medical College, Mangalore, India \\ ${ }^{2}$ Associate Professor, Department of Pathology, Fr Muller Medical College, Mangalore \\ E-mail: akshay77dias@gmail.com
}

Type of the Paper: Medical Case Study.

Type of Review: Peer Reviewed.

Indexed In: OpenAIRE.

DOI: http://dx.doi.org/10.5281/zenodo.1043523.

Google Scholar Citation: IJHSP

\section{How to Cite this Paper:}

Louis Dias, Akshay, \& Sumanth, D. (2017). Usefulness of Various Peripheral Blood Leukocyte Count rations in Malaria Evaluation. International Journal of Health Sciences and Pharmacy (IJHSP), 1(2), 52-60.

DOI: http://dx.doi.org/10.5281/zenodo.1043523.

International Journal of Health Sciences and Pharmacy (IJHSP)

A Refereed International Journal of Srinivas University, India.

(C) With Authors.

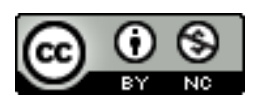

This work is licensed under a Creative Commons Attribution-Non Commercial 4.0 International License subject to proper citation to the publication source of the work.

Disclaimer: The scholarly papers as reviewed and published by the Srinivas Publications (S.P.), India are the views and opinions of their respective authors and are not the views or opinions of the SP. The SP disclaims of any harm or loss caused due to the published content to any party. 


\title{
Usefulness of Various Peripheral Blood Leukocyte Count ratios in Malaria Evaluation
}

\author{
Akshay Louis Dias ${ }^{1}$ \& Sumanth $\mathrm{D}^{2}$ \\ ${ }^{1}$ UG Scholar, Department of Pathology, Fr Muller Medical College, Mangalore, India \\ ${ }^{2}$ Associate Professor, Department of Pathology, Fr Muller Medical College, Mangalore \\ E-mail: akshay77dias@gmail.com
}

\begin{abstract}
Malaria is a major public health problem in India. Changes in blood cell counts are a wellknown feature of malaria. Hence an attempt has been made to assess the role of leucocyte ratios in malaria as predictors of malaria infection and its clinical severity. Methods: A retrospective observational cohort study was carried out in a tertiary care teaching hospital over a period of 2 months. A total of 171 samples and 48 controls were included in the study. All the absolute and differential white blood cell counts were done. The neutrophillymphocyte count ratio (NLCR), monocyte-lymphocyte count ratio (MLCR) and monocyteneutrophil count ratio (MNCR) were calculated by using the absolute neutrophil, lymphocyte and monocyte count respectively. The results were analyzed statistically using SPSS software for windows. Results: Among 171 cases 145(84.8\%), 19(11.1\%), 7(4.1\%) were Pl. vivax, Pl. falciparum and mixed malaria respectively. 52 cases were severe and 119 were non-severe. 52, 45, 47, 27 were parasitemia grade 1, 2, 3, 4 respectively. NLCR, MLCR and MNCR showed a sensitivity of $60.8 \%, 71.7 \%, 70.8 \%$ and specificity of $43.8 \%, 60.4 \%$, and $56.3 \%$ respectively in malaria diagnosis. There was no association of NLCR, MLCR, MNCR with the type and severity of malaria. NLCR, MNCR correlated with varying grade of parasitemia. Conclusion: The results show the ratios NLCR, MLCR and MNCR have a better sensitivity but less specificity. The sensitivity and specificity for MLCR are the highest and can be used as a supportive to a screening test. The ratios can be used to show the presence of malaria parasite but there is no association with the type and severity of malaria. MLCR is a good predictor of malarial presence. NLCR and MNCR are associated with parasitemia.
\end{abstract}

Keywords: Leucocyte count ratio, Predictor of Malaria, Severity.

\section{INTRODUCTION :}

Malaria is an acute and chronic illness characterized by fever, chills, sweats, fatigue, anemia and splenomegaly. It continues to be a potential public health problem in developing countries resulting in major financial burden for the government. Early and accurate diagnosis of malaria is crucial for prompt treatment of cases to reduce associated morbidity and mortality. Microscopy is gold standard for malaria diagnosis and parasite density predicts disease severity [1]. The search for the easier and less cumbersome alternative test has not been successful. Changes in leucocyte counts are well known feature in malaria:[2]. Many studies have investigated the role of peripheral blood leukocyte ratios the Neutrophil to Lymphocyte count ratio (NLCR), Monocyte to Neutrophil count ratio (MNCR) and Monocyte to Lymphocyte count ratio (MLCR) in different clinical entities like critical illness, sepsis, tuberculosis, myocardial infarction and also in malaria [2-8]. The monocytes, neutrophils, and lymphocytes play vital role in induction of immune responses to malaria infection and their parameters have been proven as predictors of malaria infection and its clinical severity [2,4,7-9]. The NLCR correlates with parasitemia and disease severity in malaria [4]. Very low MNCR and extremely high 
circulating IL-10 and IFN- $\gamma$ levels in primary complicated malaria is associated in its pathogenesis:[3]. Warimwe et al introduced the monocyte to lymphocyte count ratio (MLCR) as a risk parameter for malaria. MLCR reflects an individual's susceptibility against the clinical manifestation of Plasmodium falciparum malaria [7]. The MLCR discriminated best between malaria cases and controls, whereas the NLCR better predicted severe malaria, especially in semi immune patients. This might correlate to acquired immunity against malaria and could help to discriminate different levels of immunity ${ }^{\text {[8] }}$ MLCR is an indirect marker of an as yet unidentified mechanism important for clinical protection [10].

Mangalore, a coastal city experiences heavy rains during monsoon. The district has been witnessing a great spurt in construction activities in the recent years, owing to rapid urbanisation. Due to these reasons number vector borne infectious disease like malaria, Dengue, Chickungunya are on the rise over the years. As most of these manifests with high fever and estimation of blood counts done routinely, an attempt has been made to know the role of hematological cell count ratios as clinical parameters in evaluation of malaria. The objective of the study was to determine Sensitivity, Specificity, Positive predictive value and Negative predictive value of Neutrophil-Lymphocyte Count Ratio (NLCR), Monocyte-Lymphocyte Count Ratio (MLCR) and Monocyte-Neutrophil Count Ratio (MNCR) in malaria diagnosis. To correlate Neutrophil-Lymphocyte Count Ratio (NLCR), Monocyte-Lymphocyte Count Ratio (MLCR) and Monocyte-Neutrophil Count Ratio (MNCR) with type of malaria (Pl. vivax and $\mathrm{Pl}$. falciparum), severity of malaria and malarial parasitemia.

\section{MATERIALS AND METHODS :}

A retrospective observational cohort study was carried out in a tertiary care teaching hospital over a period of 2 months from june-2015 to July 2015, after obtaining ethical clearance from institutional ethical committee. A total of 171 samples were included. The age and sex matched random 48 non-malaria fever samples were included as controls. Malaria cases both $\mathrm{Pl}$. vivax and/or Pl. falciparum malaria with available smears and white blood cell counts were included in the study. Care was taken to collect blood counts obtained within 24 hours of admission. Patients with prior treatment history/partially treated cases, history of malaria in past 6 months and malaria due to $\mathrm{Pl}$. ovale, $\mathrm{Pl}$. malariae and $\mathrm{Pl}$. knowlesi were excluded from the study. Patients who had positive blood culture or concomitant illness like typhoid, tuberculosis, pregnancy and children below the age of 5 years were not considered.

By reviewing Laboratory data and case records, malaria cases diagnosed by peripheral smear and/or qualitative buffy coat (QBC) were identified and given unique identification number to maintain confidentiality. Both thick and thin smears of each case were retrieved from archives. The type of malaria, parasite density per microliter of blood was reassessed and reconfirmed. All the absolute and differential white blood cell (WBC) counts obtained by automated 5 part cell counter (Beckmann coulter LH 500/750) were reconfirmed by manual smear evaluation. The neutrophil-lymphocyte count ratio (NLCR), monocyte-lymphocyte count ratio (MLCR) and monocyte-neutrophil count ratio (MNCR) were calculated by using the absolute neutrophil, lymphocyte and monocyte count respectively. The cohort was divided into nonsevere and severe malaria. Severe malaria was recognized based on any of the following parameters [1].

Clinical features of severe malaria:

-Impaired consciousness (including unrousable coma);

- Prostrations, i.e. generalized weakness so that the patient is unable to sit, stand or walk without assistance;

- Multiple convulsions: more than two episodes within 24h;

- Deep breathing and respiratory distress (acidotic breathing);

- Acute pulmonary edema and acute respiratory distress syndrome;

- Circulatory collapse or shock, systolic blood pressure $<80 \mathrm{~mm} \mathrm{Hg}$ in adults and $<50 \mathrm{~mm} \mathrm{Hg}$ in children;

- Acute kidney injury;

- Clinical jaundice plus evidence of other vital organ dysfunction; and

- Abnormal bleeding. 
Laboratory and other findings:

- Hypoglycemia (<2.2mmol/l or $<40 \mathrm{mg} / \mathrm{dl})$;

- Metabolic acidosis (plasma bicarbonate < 15mmol/l);

- Severe normocytic anemia (hemoglobin <

$7 \mathrm{~g} / \mathrm{dl}$, packed cell volume $<20 \%)$;

- Severe thrombocytopenia $(<20000 / \mu 1)$;

- Haemoglobinuria;

- Hyperlactataemia (lactate $>5 \mathrm{mmol} / \mathrm{l}$ );

- Renal impairment (serum creatinine > $265 \mu \mathrm{mol} / 1)$; and

- Pulmonary edema (radiological).

All the relevant demographic information like age and sex along with type of malaria, parasite index and severity of malaria was noted in a master chart.

The results were analyzed statistically using SPSS software for windows. The frequency of percentage, mean and standard deviations were noted. The sensitivity, specificity, positive predictive value and negative predictive value were determined using Receiver operated Curve (ROC) analysis. The non-parametric results were analyzed using Kruskal-Waalis test. The Chi-square test to find association, Mann-Whitney and ANOVA to know difference between the means was utilized. A $\mathrm{p}<0.05$ was considered significant.

\section{RESULTS :}

$171($ Female $=40$, and Male $=131)$ Malaria cases were included in the study. The values were compared with 48 controls (Female $=22$, and Male = 26). Age matched Control group consisted of non-malarial fever cases. Patients were included from 6 years of age to 8 years, maximum number of cases were seen in the age group of 16-25 years. There were 145 cases of pl. vivax, 7 cases of pl. falciparum and 19 cases of mixed malaria. The distribution of parasitemia was 52, 45, 47 and 27 cases of $1+, 2+, 3+$ and $4+$ respectively. Out of 171 cases, 52 satisfied WHO criteria for severe malaria. 52 cases were severe and the other 119 were non-severe.

In the leucocyte count ratio (Table 1), NLCR was highest in vivax malaria, MLCR and MNCR in Pl. falciparum. There was no statistically significant difference between malaria types.

Table 1: Leukocyte count ratios in different types of malaria

\begin{tabular}{|l|l|l|l|l|l|}
\hline $\begin{array}{l}\text { Count } \\
\text { Ratio }\end{array}$ & $\begin{array}{l}\text { Type of } \\
\text { malaria }\end{array}$ & No. & Mean & $\begin{array}{l}\text { Standard } \\
\text { Deviation }\end{array}$ & $\begin{array}{l}\text { Standard } \\
\text { Error }\end{array}$ \\
\hline \multirow{3}{*}{ NLCR } & Pl. falciparum & 7 & 4.0994 & 1.79041 & 0.67671 \\
\cline { 2 - 6 } & Pl. vivax & 19 & 4.4145 & 2.84516 & 0.65272 \\
\cline { 2 - 6 } & Mixed & 145 & 4.4578 & 4.44057 & 0.36877 \\
\hline \multirow{3}{*}{ MLCR } & Pl. falciparum & 7 & 0.5126 & 0.36518 & 0.13803 \\
\cline { 2 - 6 } & Pl. vivax & 19 & 0.3371 & 0.25696 & 0.05895 \\
\cline { 2 - 6 } & Mixed & 145 & 0.3772 & 0.51687 & 0.04292 \\
\hline \multirow{3}{*}{ MNCR } & Pl. falciparum & 7 & 0.1617 & 0.13038 & 0.04928 \\
\cline { 2 - 6 } & Pl. vivax & 19 & 0.0951 & 0.10326 & 0.02369 \\
\cline { 2 - 6 } & Mixed & 145 & 0.1084 & 0.08352 & 0.00694 \\
\hline
\end{tabular}

NLCR and MLCR values were higher in high grade of parasitemia and MNCR showed lower values in higher grades of parasitemia (Table

2). The observed differences were significant in NLCR $(\mathrm{p}=0.009)$ and MNCR $(\mathrm{p}=0.003)$. The observations related to MLCR was not significant $(\mathrm{p}=0.333)$.

Table 2: Leukocyte count ratios in different grades of parasitemia

\begin{tabular}{|l|l|l|l|l|l|}
\hline $\begin{array}{l}\text { Count } \\
\text { Ratio }\end{array}$ & $\begin{array}{l}\text { Parasitemia } \\
\text { Grade }\end{array}$ & No & Mean & $\begin{array}{l}\text { Standard } \\
\text { Deviation }\end{array}$ & $\begin{array}{l}\text { Standard } \\
\text { Error }\end{array}$ \\
\hline \multirow{2}{*}{ NLCR } & 1.00 & 52 & 3.7296 & 1.82795 & 0.25349 \\
\cline { 2 - 6 } & 2.00 & 45 & 3.3951 & 2.36963 & 0.35324 \\
\cline { 2 - 6 } & 3.00 & 47 & 5.1988 & 3.37430 & 0.49219 \\
\cline { 2 - 6 } & 4.00 & 27 & 6.2182 & 8.49494 & 1.63485 \\
\hline
\end{tabular}




\begin{tabular}{|l|l|l|l|l|l|}
\hline MLCR & 1.00 & 52 & 0.3316 & 0.22317 & 0.03095 \\
\cline { 2 - 6 } & 2.00 & 45 & 0.3950 & 0.22667 & 0.03379 \\
\cline { 2 - 6 } & 3.00 & 47 & 0.3457 & 0.24910 & 0.03633 \\
\cline { 2 - 6 } & 4.00 & 27 & 0.4974 & 1.11637 & 0.21484 \\
\hline \multirow{5}{*}{ MNCR } & 1.00 & 52 & 0.1053 & 0.09077 & 0.01259 \\
\cline { 2 - 6 } & 2.00 & 45 & 0.1491 & 0.09936 & 0.01481 \\
\cline { 2 - 6 } & 3.00 & 47 & 0.0830 & 0.06652 & 0.00970 \\
\cline { 2 - 6 } & 4.00 & 27 & 0.0953 & 0.07676 & 0.01477 \\
\hline
\end{tabular}

The severe malaria cases showed marginal The results were not significant statistically increase in NLCR and decrease in MLCR and MNCR compared to non-severe malaria cases.

(Table 3).

Table 3: Leukocyte count ratios in malaria severity

\begin{tabular}{|l|l|l|l|l|l|}
\hline $\begin{array}{l}\text { Count } \\
\text { Ratio }\end{array}$ & $\begin{array}{l}\text { Severity of } \\
\text { Malaria }\end{array}$ & No. & Mean & $\begin{array}{l}\text { Standard } \\
\text { Deviation }\end{array}$ & $\begin{array}{l}\text { Standard } \\
\text { Error }\end{array}$ \\
\hline NLCR & Non-severe & 119 & 4.3433 & 4.60639 & 119 \\
\cline { 2 - 6 } & Severe & 52 & 4.6558 & 3.12467 & 52 \\
\hline MLCR & Non-severe & 119 & 0.4026 & 0.56585 & 119 \\
\cline { 2 - 6 } & Severe & 52 & 0.3227 & 0.22594 & 52 \\
\hline MNCR & Non-severe & 119 & 0.1117 & 0.08238 & 119 \\
\cline { 2 - 6 } & Severe & 52 & 0.1031 & 0.10078 & 52 \\
\hline
\end{tabular}

The all three ratios NLCR, MLCR, MNCR thrombocytopenia, but without any statistical showed lower values in critical significance (Table 4).

Table 4: Leukocyte count ratios and Platelet counts

\begin{tabular}{|c|c|c|c|c|c|}
\hline $\begin{array}{l}\text { Count } \\
\text { Ratio }\end{array}$ & Parasitemia Grade & No. & Mean & St. Deviation & St. Error \\
\hline \multirow[t]{5}{*}{ NLCR } & Normal & 37 & 5.0179 & 6.91012 & 1.13602 \\
\hline & Mild thrombocytopenia & 78 & 4.5164 & 3.25029 & 0.36802 \\
\hline & $\begin{array}{l}\text { Moderate } \\
\text { Thrombocytopenia }\end{array}$ & 32 & 4.2389 & 3.11159 & 0.55006 \\
\hline & Severe Thrombocytopenia & 17 & 3.7087 & 2.75816 & 0.66895 \\
\hline & $\begin{array}{l}\text { Critical } \\
\text { Thrombocytopenia }\end{array}$ & 7 & 3.1885 & 1.67471 & 0.63298 \\
\hline \multirow[t]{5}{*}{ MLCR } & Normal & 37 & 0.5209 & 0.96439 & 0.15854 \\
\hline & Mild thrombocytopenia & 78 & 0.3499 & 0.20072 & 0.02273 \\
\hline & $\begin{array}{l}\text { Moderate } \\
\text { Thrombocytopenia }\end{array}$ & 32 & 0.3069 & 0.23601 & 0.04172 \\
\hline & Severe Thrombocytopenia & 17 & 0.3655 & 0.22622 & 0.05487 \\
\hline & $\begin{array}{l}\text { Critical } \\
\text { Thrombocytopenia }\end{array}$ & 7 & 0.2996 & 0.27799 & 0.10507 \\
\hline \multirow[t]{2}{*}{ MNCR } & Normal & 37 & 0.1172 & 0.09386 & 0.01543 \\
\hline & Mild thrombocytopenia & 78 & 0.1027 & 0.07526 & 0.00852 \\
\hline
\end{tabular}




\begin{tabular}{|l|l|l|l|l|l|}
\hline & $\begin{array}{l}\text { Moderate } \\
\text { Thrombocytopenia }\end{array}$ & 32 & 0.1001 & 0.08150 & 0.01441 \\
\cline { 2 - 5 } & Severe Thrombocytopenia & 17 & 0.1438 & 0.13087 & 0.03174 \\
\cline { 2 - 5 } & $\begin{array}{l}\text { Critical } \\
\text { Thrombocytopenia }\end{array}$ & 7 & 0.0950 & 0.09855 & 0.03725 \\
\hline
\end{tabular}

NLCR increased in mild and decreased in moderate and severe anemia, the results were statistically significant $(\mathrm{p}=0.023)$. MLCR increased in mild and moderate anemia, MNCR decreased in mild and increased in moderate anemia, but MLCR $(\mathrm{p}=0.270)$ and

MNCR $\quad(\mathrm{p}=0.0237)$ were statistically insignificant (Table 5). The area under the curve is highest for MLCR and lowest for NLCR (Table 6). The sensitivity and specificity is highest with MLCR and lowest with NLCR which is showed in Table 7.

Table 5: Leukocyte count ratios and Haemoglobin

\begin{tabular}{|l|l|l|l|l|l|}
\hline $\begin{array}{l}\text { Count } \\
\text { Ratio }\end{array}$ & Haemoglobin & No & Mean & $\begin{array}{l}\text { Standard } \\
\text { Deviation }\end{array}$ & $\begin{array}{l}\text { Standard } \\
\text { Error }\end{array}$ \\
\hline \multirow{4}{*}{ NLCR } & Normal & 147 & 4.3036 & 4.36206 & 0.35978 \\
\cline { 2 - 6 } & Mild anaemia & 19 & 5.7208 & 3.11339 & 0.71426 \\
\cline { 2 - 6 } & Moderate anaemia & 4 & 4.1371 & 1.55562 & 0.77781 \\
\cline { 2 - 6 } & Severe anaemia & 1 & 1.0833 &. &. \\
\hline \multirow{4}{*}{ MLCR } & Normal & 147 & 0.3783 & 0.51673 & 0.04262 \\
\cline { 2 - 6 } & Mild anaemia & 19 & 0.3908 & 0.25701 & 0.05896 \\
\cline { 2 - 6 } & Moderate anaemia & 4 & 0.4146 & 0.31288 & 0.15644 \\
\cline { 2 - 6 } & Severe anaemia & 1 & 0.0000 &. &. \\
\hline MNCR & Normal & 147 & 0.1128 & 0.08949 & 0.00738 \\
\cline { 2 - 6 } & Mild anaemia & 19 & 0.0836 & 0.06798 & 0.01560 \\
\cline { 2 - 6 } & Moderate anaemia & 4 & 0.1217 & 0.11852 & 0.05926 \\
\cline { 2 - 6 } & Severe anaemia & 1 & 0.0000 &. &. \\
\hline
\end{tabular}

Table 6: Leukocyte count ratios - ROC analysis derivatives

\begin{tabular}{|l|l|l|l|}
\hline Count Ratio & Area & Std. Error $^{\mathbf{a}}$ & Asymptotic Sig. $^{\mathbf{b}}$ \\
\hline NLCR & 0.515 & 0.053 & 0.749 \\
\hline MLCR & & & 0.000 \\
\hline MNCR & 0.670 & 0.048 & 0.002 \\
\hline
\end{tabular}

a. Under the nonparametric assumption b. Null hypothesis: true area $=0.5$

Table 7: Leukocyte count ratios - Predictive value and ROC analysis

\begin{tabular}{|l|l|l|l|l|l|l|}
\hline $\begin{array}{l}\text { Count } \\
\text { ratio }\end{array}$ & $\begin{array}{l}\text { Cut -Off } \\
\text { Value }\end{array}$ & Sensitivity & Specificity & $\begin{array}{l}\text { Positive } \\
\text { Predictive } \\
\text { Value }\end{array}$ & $\begin{array}{l}\text { Negative } \\
\text { Predictive } \\
\text { Value }\end{array}$ & $\begin{array}{l}\text { Diagnostic } \\
\text { Accuracy }\end{array}$ \\
\hline NLCR & $>/=2.887$ & $60.8 \%$ & $43.8 \%$ & $79.4 \%$ & $23.9 \%$ & $57.1 \%$ \\
\hline MLCR & $>/=0.206$ & $71.9 \%$ & $60.4 \%$ & $86.6 \%$ & $37.7 \%$ & $69.4 \%$ \\
\hline MNCR & $>/=0.057$ & $70.8 \%$ & $56.3 \%$ & $85.2 \%$ & $35.1 \%$ & $67.6 \%$ \\
\hline
\end{tabular}




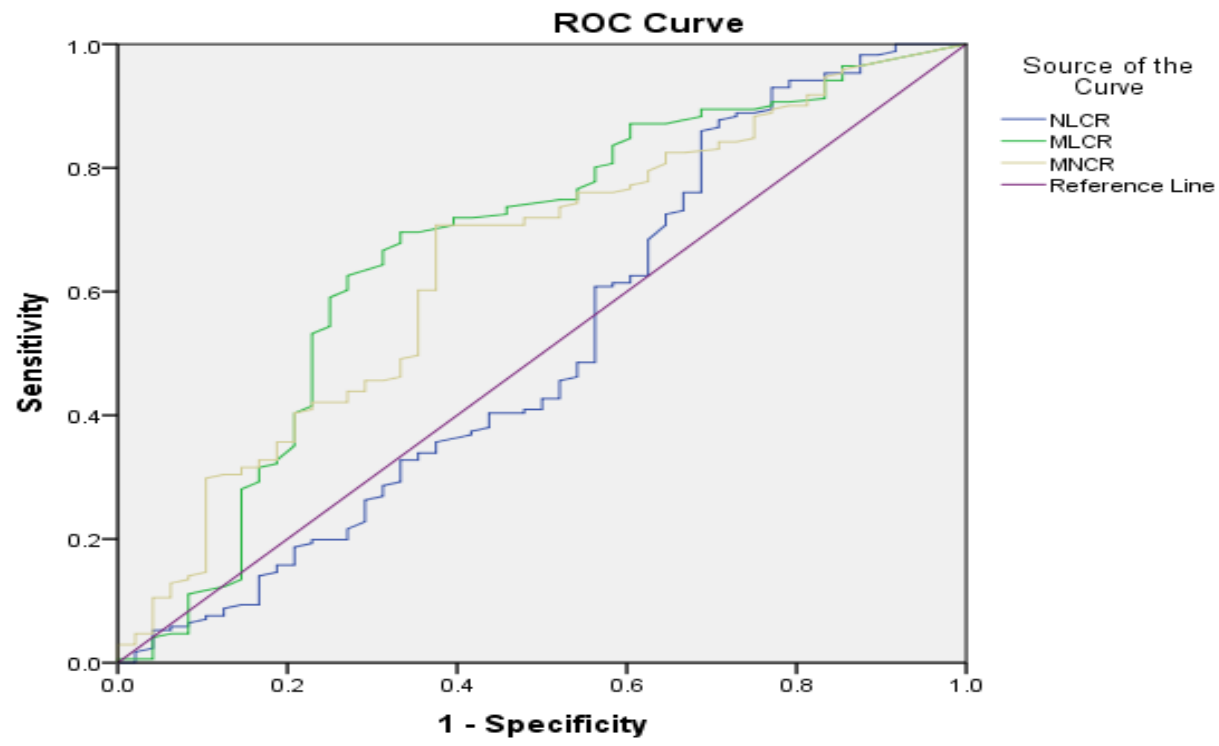

Fig. 1 : ROC Analysis

\section{DISCUSSION :}

Inflammatory cells play a key role in defence against any invading organism in human body. The initial rapid response to infections is by neutrophils with resultant acute inflammation. The inability of this response to clear the offenders results in protracted phase of chronic inflammation, bringing in lymphocytes and macrophages [11] The neutrophils and monocytes are the primary line of defence against malaria. T-helper cells regulate this acquired immunity. The inflammatory mediators take part in this process and IFN- $\gamma$ is the key molecule in effect or mechanism [4]. The host defense mechanism is same, irrespective of Plasmodium species.

Under these conditions, alterations in leukocyte counts are expected in malarial infections. Many studies investigated the options of using hematological parameters as malarial diagnostic tool. The results are variable rendering them unreliable parameters [12] Hence, we evaluated role of leukocyte ratios in malarial infections.

\section{The Neutrophil-Lymphocyte Count Ratio (NLCR):}

The NLCR was introduced by Zahorec R [3] as a simple parameter for critical illness, further predicted major adverse cardiac events in diabetics [5] and classification of Tuberculosis [6].
By hypothesis NLCR should be more in acute malarial infections and in severe malarial infections. Our NLCR sensitivity and specificity was almost similar to a study by van Wolfswinkel et al [2] (Table-8) and observation that NLCR did not allow for an accurate discrimination between malaria patients with severe disease and those without, this is in contrast to study by Zahorec R [3] on bacterial sepsis.

We agree with van Wolfswinkel et al [2] explanation that the variation in neutrophil count seen in malaria is responsible for this discordance. In severe malaria, the immature neutrophil fraction increases due to premature release from bone marrow and circulating pool decreases due to shift of neutrophils to margination pool. The increased cytoadh erence due to elaboration of TNF- $\alpha$ causes this particular change. An acute TNF-alpha overproduction eventually leads to development of severe malaria [12]. Hence, Neutrophils may not increase with severity of malaria. NLCR in various studies is shown in table 8. 
Table 8 : NLCR in various studies

\begin{tabular}{|l|l|l|l|l|l|}
\hline Study Name & $\begin{array}{l}\text { Cut-Off } \\
\text { Value }\end{array}$ & Sensitivity & Specificity & $\begin{array}{l}\text { Positive } \\
\text { Predictive } \\
\text { Value }\end{array}$ & $\begin{array}{l}\text { Negative } \\
\text { Predictive } \\
\text { Value }\end{array}$ \\
\hline Present Study & $\geq 2.887$ & $60.8 \%$ & $43.8 \%$ & $79.4 \%$ & $23.9 \%$ \\
\hline $\begin{array}{l}\text { Wolfswinkel et } \\
\mathbf{a l}^{\mathbf{2}}\end{array}$ & $\geq 2.8$ & $77 \%$ & $44 \%$ & $18 \%$ & $92 \%$ \\
\hline $\begin{array}{l}\text { Berens-Riha et } \\
\mathbf{a l}^{\mathbf{8}}\end{array}$ & $\geq 1.5$ & - & - & - & - \\
\hline Kotepui et al $^{\mathbf{3 0}}$ & $\geq 2.8$ & $49 \%$ & $61 \%$ & $17 \%$ & $88 \%$ \\
\hline
\end{tabular}

\section{The Monocyte-Lymphocyte Count Ratio (MLCR):}

This parameter had highest area under ROC Curve and better sensitivity, specificity and diagnostic accuracy. This supports the observation of Warimwe et al [7] and Kotepui et al [13]. Monocyte count is high in uncomplicated malaria and low in severe malaria. Monocyte count is also associated with parasitemia. We did not find any significant association with malaria severity and parasitemia, although trend was similar to other studies. The possible explanation is that our study group and control group were from endemic region with possible alteration of these ratios in control group. We used light microscopy rather than PCR-based parasite detection methods. It is possible that some of the parasite negative controls might have had asymptomatic malaria infection with very low parasitemia, below the detection limit of light microscopy or had immune response to fight any future parasitemia. Future studies detecting malaria infections by the more sensitive PCR methods will help provide a better assessment of MLCR in malaria endemic regions. The possible re-emergence of lymphocytes from sequestration sites to mount immune response in endemic region might also been responsible for insignificant MLCR, which again needs to be evaluated by study. Table 9 shows MLCR in various studies.

Table 9: MLCR in various studies

\begin{tabular}{|l|l|l|l|l|l|}
\hline Study Name & $\begin{array}{l}\text { Cut -Off } \\
\text { Value }\end{array}$ & Sensitivity & Specificity & $\begin{array}{l}\text { Positive } \\
\text { Predictive } \\
\text { Value }\end{array}$ & $\begin{array}{l}\text { Negative } \\
\text { Predictive } \\
\text { Value }\end{array}$ \\
\hline Present Study & $\geq 0.206$ & $71.9 \%$ & $60.4 \%$ & $86.6 \%$ & $37.7 \%$ \\
\hline $\begin{array}{l}\text { Berens-Riha et al } \\
\text { (Non-immune) }\end{array}$ & $\geq 0.27$ & $59 \%$ & $80 \%$ & $67.5 \%$ & - \\
\hline Kotepui et al $^{\mathbf{3 0}}$ & $\geq 0.25$ & $58 \%$ & $54 \%$ & $17 \%$ & $89 \%$ \\
\hline
\end{tabular}

Monocyte-Neutrophil Count Ratio (MNCR):

As these cells are the principle cells involved in malaria pathogenesis, we thought it is prudent to evaluate this parameter. The studies using this parameter are scarce in literature. The diagnostic significance of this ratio in our study is almost similar to that of MLCR. As monocytes and neutrophils are the cells involved in clearance of parasitemia, the association with parasitemia was expected. The absence of any significant relation of this parameter with severity of malaria and increase with parasitemia is contrast to study by Tangteerawatana et al [4]. Their study comprised only of Pl. falciparum $(\mathrm{n}=279)$ and pl. falciparum were minority in our study. The malaria endemicity would have given better acquired immunity resulting in higher MNCR. The mechanism of anemia and thrombocytopenia observed in malaria is due to splenic sequestration. The absence of significant correlation of platelet counts and hemoglobin with leukocyte ratios is in accordance with this.

\section{CONCLUSION :}

The results show the ratios NLCR, MLCR and MNCR have a better sensitivity but less specificity. The sensitivity and specificity for 
MLCR are the highest and can be used as a supportive to a screening test. The precision (positive predictive value) of all 3 ratios is highest among the parameters and suggests that the ratios can be used to show the presence of malaria parasite. The MLCR shows a sensitivity of $71.9 \%$ and a diagnostic accuracy of $69.4 \%$. This shows that MLCR is a good predictor of malarial presence. MLCR also shows a specificity of $60.4 \%$ and a negative predictive value of $37.7 \%$ showing that it is an average indicator of malarial absence. The ratios NLCR, MLCR, MNCR have shown no association with the type and severity of malaria. NLCR and MNCR are associated with parasitemia and NLCR and MNCR vary with grade of parasitemia.

\section{REFERENCES :}

[1] World Health Organization: Management of severe malaria: A practical Handbook 3rd edition.2012.

[2] Wolfswinkel M, VliegenthartJongbloed K, Melo M, Wever P,McCall M, Koelewijn $\mathrm{R}$ et al. Predictive value of lymphocytopenia and the neutrophillymphocyte count ratio for severe imported malaria. Malar J 2013; 12:101.

[3] Zahorec R. Ratio of neutrophil to lymphocyte counts - rapid and simple parameter of systemic inflammation and stress in critically ill. Bratisl Lek Listy 2001;102:5-14.

[4] Tangteerawatana P, Krudsood S, Kanchanakhan N, Troye-Blomberg M, Khusmith S. Low monocyte to neutrophil ratio in peripheral blood associated with disease complication in primary Plasmodium Falciparum infection. Southeast Asian J Trop Med Public Health 2014;45:517-30.

[5] Lee GK, Lee LC, Chong E, Lee CH, Teo SG, Chia BL and Poh KK. The long-term predictive value of the neutrophil-tolymphocyte ratio in Type 2 diabetic patients presenting with acute myocardial infarction. Q J Med 2012 doi:10.1093/qimed/hcs123.
[6] Sutherland J, Jeffries D, Donklor S, Walther B, Hill P, Adetifa I et al. High granulocyte/lymphocyte ratio and paucity of NK-T cells defines TB disease in a TBendemic setting. Tuberculosis 2009;89:398-404.

[7] Warimwe GM, Murungi LM, Kamuyu G, Nyangweso GM, Wambua J, Naranbhai V, Fletcher HA, Hill AV, Bejon P, Osier $\mathrm{FH}$, Marsh K: The ratio of monocytes to lymphocytes in peripheral blood correlates with increased susceptibility to clinical malaria in Kenyan children. PLoS One 2013;8:e57320

[8] Berens-Riha N, Kroidl I, Schunk M, Alberer M, Beissner M, Pritsch $\mathrm{M}$ et al. Evidence for significant influence of host immunity on changes in differential blood count during malaria. Malar $J$ 2014;13:155.

[9] Kinyanjui SM, Conway DJ, Lanar DE and Marsh K. IgG antibody responses to Plasmodium falciparum merozoite antigens in Kenyan children have a short half-life. Malar J 2007;6:82.

[10] Warimwe GM, Fletcher HA, Olotu A, Agnandji ST, Hill AVS, Marsh $\mathrm{K}$ and Bejon P. Peripheral blood monocyte-to-lymphocyte ratio at study enrollment predicts efficacy of the RTS,S malaria vaccine: analysis of pooled phase II clinical trial data. BMC Medicine 2013;11:184.

[11] Kumar V, Abbas AK, Aster JC, editors. Pathologic basis of disease. 9th ed. Canada: Elsevier Saunders; 2015 .

[12] Senaldi G, Vesin C, Chang R, Grau GE and Piguet PF. Role of Polymorphonuclear Neutrophil Leukocytes and Their Integrin CD11a (LFA-1) in the Pathogenesis of Severe Murine Malaria. Infection and Immunity 1994;62:1144-1149

[13] Kotepui M, Phunphuech B, Phiwklam N, Chupeerach $C$ and Duangmano S. Effect of malarial infection on haematological parameters in population near ThailandMyanmar border. Malar J 2014;13:218 